\title{
Cognitive dysfunction syndrome: updated behavioral and clinical evaluations as a tool to evaluate the well-being of aging dogs
}

\author{
Síndrome de disfunción cognitiva: actualización del conocimiento como herramienta para el \\ bienestar animal en perros seniles
}

\author{
S Pineda, A Olivares, B Mas, M Ibañez*
}

Centro de Medicina del Comportamiento, Departamento de Producción Animal, Facultad de Veterinaria, Universidad Complutense de Madrid, Madrid, España.

\begin{abstract}
RESUMEN
La mejora en la atención veterinaria, la nutrición y el enriquecimiento del entorno doméstico ha facilitado que cada vez haya un mayor número de perros que vivan su etapa senil. Sin embargo, se debe tener en cuenta que una mayor longevidad implica una mayor prevalencia de problemas cognitivos en nuestras mascotas. A lo largo de su vida geriátrica los perros son más vulnerables a padecer síndromes demenciales neurodegenerativos de carácter progresivo. Una de las enfermedades neurodegenerativas que actualmente está siendo objeto de estudio por su elevada prevalencia es el síndrome de disfunción cognitiva. La enfermedad es una entidad neurocomportamental que se presenta en perros ancianos, caracterizado por un déficit en el aprendizaje, en la memoria y en la conciencia espacial del perro, además de ser un trastorno clínico que tiene un impacto significativo en la vida de los perros de edad avanzada y sus propietarios. La escasez de pruebas diagnósticas de alta confiabilidad que garanticen la presencia o no de la enfermedad, otorga a la identificación temprana de los signos clínicos, un papel crucial para el establecimiento de un buen pronóstico en términos de mejoría y extensión en la calidad de vida de los pacientes afectados. El tratamiento debe dirigirse a frenar la progresión de la pérdida de cognición, mediante la instauración de técnicas y programas que mejoren la actividad física, los aspectos nutricionales y el ambiente del animal. Por lo tanto, son necesarias futuras investigaciones en el conocimiento, control y prevención de esta patología, para disminuir el impacto generado por sus efectos sobre la calidad de vida de los perros y sus propietarios.
\end{abstract}

Palabras clave: síndrome de disfunción cognitiva, perros, proteína $\beta$-amiloidea.

\section{SUMMARY}

Improvements in veterinary medicine, nutrition and the enrichment of the domestic environment have helped more dogs reach to their senile phase. However, greater longevity leads to a higher prevalence of cognitive problems in our pets. Throughout their geriatric lives, dogs are more vulnerable to suffering progressive neurodegenerative dementia syndromes. Due to its high prevalence, cognitive dysfunction syndrome is one of the most studied neurodegenerative diseases. This disease is a neurobehavioral entity that presents itself in senile dogs, and it is characterized by a deficit in learning, memory and the dog's spatial awareness. It is a clinical disorder that has a significant impact on older dogs and their owners. There is a lack of reliable diagnostic tests that can guarantee the presence of the disease, provide early identification of the clinical signs of this disease, or establish a prognosis in terms of the recovery and expansion of the quality of life of the affected patient. Treatment should be directed at slowing down the progression of cognitive loss through the establishment of techniques and programs that improve physical activity, nutrition and the animal's environment. Therefore, future research on the knowledge, control and prevention of this pathology are necessary to lower the impact generated by its effects on the quality of life of the animal.

Key words: cognitive dysfunction syndrome, dogs, $\beta$-amyloid protein.

\section{INTRODUCTION}

Interest in the study of the brain's aging process and the behavioral changes linked to the age of senile dogs has increased in the last decade, a consequence of the increase in the prevalence of cognitive dysfunction problems (Landsberg and Ruehl 1997).

Accepted: 02.05.2013.

* mibanez@vet.ucm.es
Due to improvements in veterinary service, nutrition and the enrichment of the domestic environment, there are more dogs living to their senile phase. In fact, some authors have calculated that $25 \%$ to $50 \%$ of the dogs in Europe are older than 7 years old, and in the United States, more than 7.3 million dogs reach age 10 (Bonagura 2000). However, greater longevity leads to a higher prevalence of cognitive problems in our pets (Crook and Larrabee 1991). For this reason, it is necessary for the majority of owners to address the aging process and for veterinarians to be more knowledgeable on the physical and mental consequences of aging. 
Throughout their geriatric life, dogs, just like humans, are more vulnerable to suffering progressive neurodegenerative dementia syndromes (Borras et al 1999, Head 2001). In humans, one of the most important neurodegenerative disorders is Alzheimer's disease (AD), while in canines, one of the most important neurobehavioral syndromes is cognitive dysfunction syndrome (CDS), or canine counterpart of Alzheimer's disease (Ruehl et al 1995). These types of pathologies are associated with central nervous system disorders during the process of aging (Pérez- Guisado 2007).

Canine cognitive dysfunction, or "canine dementia," is a neurobehavioral syndrome that presents itself in senile dogs; it is characterized by learning, memory and spatial awareness deficits in the dog. Likewise, there are alterations in social interactions and sleeping patterns (Landsberg et al 2003). However, some authors state that there is a certain degree of physiological declination in senescence that determines a decrease in the speed of information recompilation, processing, holding and decision-making (Head 2001, Boutet et al 2005).

Some authors have outlined the similarities between the changes associated with age in human and canine brains, concluding that dogs may serve as a useful model for the extrapolation of Alzheimer's disease and other human neurodegenerative illnesses in aging studies (Borras et al 1999).

Due to the similarities between these two dementia syndromes in humans and dogs, studies in senile dogs with CDS are a useful tool for the recognition of some clinical and pathological aspects of $\mathrm{AD}$ that have not yet been clarified in humans and may therefore facilitate more efficient management of the disease (Cummings et al 1995, Ikeda-Douglas et al 2005). However, despite these similarities and the link between many of the predisposing factors for both these pathologies, some differences also exist between these pathologies. Some studies have identified the contribution of other factors that predispose humans, but not canines, to diseases such as $\mathrm{AD}$, including positive family records (Jorm 2000) and genetic susceptibility (positive APOE e4 gene, APP, PSEN1, PSEN2) (Caermelli et al 1999, Wang et al 2008 ,). The brains of human AD patients display typical microscopic characteristics, including the presence of neurofibrillary tangles (NFTs), Hirano bodies (HBs), and granulovacuolar degeneration bodies (GVDs) in the parietal cortex and hippocampus. Microscopically, the brains of aged dogs with cognitive dysfunction exhibit neuronal depletion and vascular hypertrophy in the cerebral cortex and hippocampus. However, NFTs, HBs, and GVDs are not found. The reason for the absence of these protein aggregates in dogs with cognitive decline remains poorly understood. One presumption is that the earlier death of dogs precludes this protein accumulation (Yu et al 2011). Yu et al (2011) detected moderate levels of ubiquitin in the cerebral cortices and hippocampi of humans with Alzheimer's disease. In the brains of aged dogs with SDC, ubiquitinated bodies were detected in $83 \%$ of the cases. Despite the great progress that comes with the use of an experimental model, such as that from dogs that develop a neurodegenerative disease with many similarities to that observed in humans (Cummings et al 1995), the results obtained from the use of this model will not always reproduce information that permits complete extrapolation from animals to humans. The techniques employed to evaluate cognitive functions differ in their ability to qualify certain functions, such as the perception, differentiation, storage, and recuperation of cognitive flexibility (Boutet et al 2005).

For a dog, reaching the senile stage implies the development of certain cognitive changes. Some dogs grow old without experiences any progress in cognitive dysfunction, while others may exhibit mild or pathological cognitive changes.

Age-related neuropathology in dogs was first observed by Lafora in 1914, when he reportedanomalies in the dendrites of hippocampal pyramidal cells, a finding similar to that observed in humans. In 1997, this syndrome was described by Landsberg and Ruehl as an entity that not only causes behavioral problems but also leads to a deterioration of the organs and sensory functions as well as a decrease in cognitive function (Landsberg and Ruehl 1997). The disease was observed in dogs over 9 years old (Ingram and Williams 2002), and it was established that this disease is caused by chemical and physical changes in the brain that are attributable to normal aging (Godoy 2004).

\section{EPIDEMIOLOGY OF COGINITIVE DYSFUNCTION SYNDROME IN DOGS}

Some studies show that the CDS is very prevalent and under-diagnosed, and it exerts a significant impact on the life of elder dogs and their owners (Salvin et al 2010). While many studies on the prevalence of CDS have identified CDS as a common problem in old dogs (Neilson et al 2001, Osella et al 2007, Azkona et al 2009), epidemiology studies suggest that the disease is under-diagnosed in up to $85 \%$ of potentially affected animals (Salvin et al 2010). Its prevalence has not been established in many countries of Europe or America, but a poll taken by 981 owners of dogs older than 7 years in the United Kingdom suggested that approximately one-third of the dogs showed signs of confusion, restlessness and less enjoyment of life, while 1 out of 5 showed an increase in the incidence of habitual hygiene problems (Heath et al 2007). A study conducted in Italy that included 124 geriatric dogs showed a CDS prevalence of nearly $50 \%$, in which 75 dogs over 7 years old showed signs that correlated with the disease (Osella et al 2007). An American study included 97 bitches and 83 castrated dogs, all between the ages of 11 and 16 . The results of this study showed that 28\% of dogs 11-12 years 
old showed alterations in one or more of the behavioral categories linked to CDS (orientation, interaction with people and other animals, alterations in sleep and guard, inappropriate elimination) (Landsberg et al 2003) and that $10 \%$ showed alterations in two or more behavioral categories. On the contrary, $68 \%$ of the dogs aged $15-16$ showed alterations in one or more categories, and 35\% showed alterations in two or more categories (Neilson et al 2001). Regarding gender, females showed a higher prevalence of behavioral alterations linked to CDS $(76 \%)$ than males (65\%) (Godoy 2004).

These conclusions suggest that, just like in humans, increasing age is a determinant factor of the prevalence of these types of diseases (Adams et al 2000, Bain et al 2001, Neilson et al 2001, Azkona et al 2009). Nevertheless, data concerning the global prevalence of this syndrome have not been obtained, partially due to the tendency of a great number of owners to not report the possible behavioral changes in their senile pets to the veterinarian. Additionally, many owners probably assume that these changes are untreatable aspects of age, which has most likely limited the acquisition of precise data that could help estimate the prevalence of CDS on a global level (Osella et al 2007).

\section{PHYSIOPATHOLOGY OF COGNITIVE DYSFUNCTION SYNDROME IN DOGS}

From a physiological point of view, CDS also presents organic disorders that have been widely studied with diagnostic clinical tools. CDS is a complete physiopathological process in which one of the early events is oxidative damage linked to age (Anderson et al 2001, Milgram et al 2002, Cotman et al 2002, Skoumalova et al 2003, Rofina et al 2004).

The mitochondrial genome participates in the pathogenesis of these diseases, as there is a decrease in the activity of the respiratory chain complex. These defects are associated with an oxidative-antioxidative imbalance, in which underlying alterations in energetic metabolism induce cellular degeneration (Cumsee et al 2006). It has been demonstrated that both mitochondrial dysfunction and apoptosis contribute to the development and progression of mitochondrial and degenerative diseases (Liu et al 2009). The brain is particularly susceptible to oxidative damage due to its high oxygen consumption ratio, high energy demand, great abundance of polyunsaturated fatty acids and lipids and its relative antioxidant capacity compared to other organs. Generally, $2 \%$ of the oxygen consumed by cells during oxidative phosphorylation turns into ROS (reactive oxygen species), suggesting that oxidative damage may be an early factor in this disease's pathogenesis (Cerdá et al 2009). Studies show that both the extension of oxidative injury and the amyloid load are related to the severity of the dysfunction in both cats and dogs (Cummings et al 1996, Rofina et al 2004).
The central nervous system's characteristic senile plaques are injuries of the neuropil, a spheroid structure found in the extraneural space. Neuropil is mostly composed of a protein called $\beta$-amyloid (Guimera et al 2002), which is a peptide of variable length between 39 to 43 amino acids and a size of 4-6 kDa. This protein is a natural product of the metabolism of the amyloid forerunner protein, which possesses the structural characteristics of a membrane protein (Gra et al 2002). It has been reported that an increase in $\beta$-amyloid deposits is directly related to the severity of CDS in dogs (Landsberg et al 2003). Some years ago, a third type of deposit was discovered called ubiquinated bodies, which are mainly made of ubiquitin, a small protein composed of 76 amino acids; this protein folds itself into a compact globular structure. Its name is based on its abundance and ubiquity. This protein is only found in eukaryotic organisms, where it appears in a free form or covalently linked to other proteins (Briones et al 2010).

Studies performed by Briones et al (2010) in canine brains older than 10 years showed the presence of the same abnormal protein deposits that are present in human Alzheimer's disease, such as senile plaques, ubiquinated bodies, and amyloid angiopathy, but they did not find any neurofibrillary tangles. These tangles are composed mainly of a protein called tau, which is the main representative of a class of proteins associated to microtubules, usually called MAPs (Microtubule-Associated Proteins) (Morelli and Castaño 2004). This protein facilitates a process of hyperphosphorylation that results in the formation of paired helical filaments, which saturate the cytoplasm and generate the destruction of microtubules and neurofilaments, promoting neuronal dysfunction (Goedert 1993, Pérez 2007ª). Tau pathology has been studied in animal brains, but neurofibrillary tangles (NFTs) have not been observed in the brains of aged dogs (Uchida et al 1992). Neurofibrillary plaques are not common in other species, and they are one of the main differences that exist between SDC and EA, as dogs do not develop these structures. This is partially because the tau protein sequence is different in dogs than in humans, which could affect the formation of double helix filaments and ultimately the formation of plaques. However, recent studies suggest that incipient plaques in the brains of aged dogs most likely do not reach maturity (Head 2001). The phosphorylation sites of tau in the canine brain have been studied, but these have not been fully elucidated. The phosphorylation of tau-1 sites, such as Ser189 and 207 of the amino acid sequence, has been reported in dogs (Wegiel et al 1998), but Colle et al (2000) demonstrated that the brains of aged dogs were not labeled by an antibody that recognizes human phosphorylated Ser194 and Ser202 residues.

Additionally, Pugliese et al (2006) showed a concurrent but spatially independent presence of amyloid diffuse plaques and tau hyperphosphorylation in the bra- 
ins of dogs with CDS, along with augmentation of tau hyperphosphorylation, immunoreactivity and an increase in cognitive deficits. In the absence of clinical signs of cognitive dysfunction, discrete tau hyperphosphorylation in animals with slight cognitive deficits may reflect normal aging in dogs (Pugliese et al 2005). Because the presence of cognitive dysfunction, whether slight or severe, is also age-dependent, further experiments performed with a large number of animals are needed to properly interpret the relationship between aging, cognitive dysfunction, and tau phosphorylation (Pugliese et al 2006).

In the same study, the majority of the canines (70\%) showed signs of dysfunction at the time of the survey. The dogs that showed a higher prevalence of dysfunction were those older than 15 years $(88 \%)$, indicating that higher age is associated with more ubiquitin deposits and greater cognitive deterioration. Therefore, it can be speculated that ubiquitin bodies may be one of the causes of cognitive impairment in geriatric dogs. It has been shown that $\beta$-amyloid is a deposit related to normal aging rather than to pathology, which conflicts with the results of other studies, such as that of Mentzel (2005), who argues that cognitive impairment is associated with a more extensive formation of plaques (Briones $e t$ al 2010).

Recent research indicates that brain aging could be related to an alteration of the corticotrophic axis and the production of cortisol (Laughlin and Barret-Connor 2000, Ferrari et al 2001). Other studies have evaluated the association between dehydroepiandrosterone levels (DHEA) and the cortisol hormone throughout the determination of blood parameters, with the aim of establishing the impact of this association on the aging of the brain (Villegas et al 2011). These authors found that cortisol levels tended to increase with age, and when the influence of gender was evaluated, geriatric females with cognitive impairment showed significantly higher cortisol levels than healthy females of the same age.

On the other hand, it is important to emphasize the presence of abnormal brain neurotransmitter levels in the pathophysiological changes that occur in CDS in dogs, such as the documented decrease in the levels of dopamine and the D2 dopamine receptor. In some primates that have suffered from cognitive dysfunction, low levels of norepinephrine have also been found (Osella et al 2005). Both these catecholamines and the serotoninergic system are affected. It has been observed that the brain levels of this neurotransmitter and its metabolites in the cerebrospinal fluid are low in neurodegenerative diseases (Osella et al 2005). Monoamine oxidase (MAO) is increased in old animals, so it may influence the observed decrease in levels of these neurotransmitters (Rosaldo 2006). Decreases in the learning capacity as a consequence of aging seem to be related to alterations in the function of the hippocampus and its cortex-directed projections (Manteca 2003).
Other characteristics of CDS in dogs include the dilatation of the brain ventricles, alterations in brain circulation that reduce blood flow, a decreased number of neurons in the brain and cerebellum, meningeal fibrosis, white substance degeneration, atrophy of the central nervous system (CNS), decreased action of neurotransmitters (serotonin, acetylcholine and dopamine), and an increase in the existence of monoamine oxidase B. MAOB controls the catabolism of dopamine, resulting in a greater liberation of free radicals with an affinity for the unsaturated fatty acids present in the cellular membrane, which produces membrane damage and cellular death (Landsberg 1998, Campbell et al 2001, Milgram et al 2002, Rofina et al 2004). It is rare to find atherosclerosis, ischemia and brain hemorrhage in old dogs; however, there can be microhemorrhages and infarctions in blood vessels located around the brain ventricles with a higher frequency. Non-lipidic atherosclerosis is commonly observed in dogs due to the fibrosis of the blood vessel walls, a proliferation of the vascular endothelium, hyalinization and mineralization. These types of angiopathies may compromise blood flow towards the brain and the use of glucose (Landsberg et al 2003).

\section{CLINICAL SIGNS OF THE DISEASE}

In CDS, the term "cognition" refers to mental processes such as perception, conscience, learning, memory and decision-making, which allow the individual to obtain information from the environment and make decisions, act and function in a normal way (Shettleworth 2001). In this sense, the cognitive deficit observed in patients with CDS refers to a decreased capacity to obtain information, process it, retain it and make decisions that result in behavioral changes (Head 2001, Landsberg 2005).

The most notorious clinical signs are changes in behavior, which tend to be mild during the initial stages of the disease and gradually progress, with the eventual appearance of manifestations of memory loss, such as the inability to recognize family members, forgetting things that were once learned, difficulty in performing simple tasks, alterations in the sleep-wake cycle and inappropriate elimination as a result of the inability to remember formerly established elimination places (Head 2001, Campbell et al 2001). Phobic processes that did not originally exist may appear, and the pet's insecurity may limit its social interaction. Likewise, signs of separation anxiety, aggressiveness and compulsive problems may be observed, which may lead to disorders in social relations (Landsberg 1998) and result in the rejection of some owners to assume the care of their pets, increasing their risk of being abandoned or put down (Gallego et al 2010).

Signs of behavioral alterations in geriatric dogs are sometimes considered to be normal features of the aging process; however, it is important to differentiate between these mild decreases in psychomotor activity, or "normal 
aging," and those that are related to serious damage of the cognitive processes, i.e., "pathological aging" (Rofina et al 2001, Head and Zicker 2004, Osella et al 2007).

\section{DIAGNOSIS}

Normal cognitive aging is complex, and there are many difficulties that lead to the establishment of a correct diagnosis that may allow for the differentiation of the physiological process of aging from a pathological process related to dementia (Lorenzo et al 2003). The scarcity of trustworthy diagnostic tests that can guarantee the presence or absence of the disease, allow for the early identification of clinical signs, and help establish the prognosis in terms of improvement and the extension of the affected patients' life span (Gallego et al 2010).

In geriatric human beings, as well as in geriatric dogs, several metabolic and functional diseases should be considered before excluding a diagnosis of dementia (AD and CDS, respectively). Therefore, the most useful diagnostic algorithm should encompass a complete physical and neurologic evaluation, a complete blood profile, biochemical assessment, urine analysis, and abdominal ultrasound to evaluate the presence of metabolic diseases (Windsor and Olby 2007) before utilizing advanced diagnostic imaging.

However, it should be noted that diagnosing a medical condition does not exclude the possibility of concurrent unrelated cognitive dysfunction (Frank 2002). The diagnosis of CDS is made by pathological assessment once other medical and behavioral causes are ruled out (Landsberg et al 2011).

\section{IMAGING DIAGNOSIS}

There are several studies that have demonstrated the usefulness of different diagnostic techniques for CDS, including nuclear magnetic resonance (NMR), positron emission tomography (PET), lumbar puncture (LP), computed axial tomography of the cranium (CAT), brain biopsy, biological markers, genetic studies and diagnostic ultrasound (Llibre and Guerra 1999).

Magnetic resonance imaging (MRI) has been used as a noninvasive and useful diagnostic technique for evaluating age-related brain disorders, such as Alzheimer's disease, Parkinson's disease, and dementia, indicating the severe atrophy of the brain, hippocampus, amygdala, temporal lobe, and gray matter and the dilatation of the ventricle space and cortical sulci (Drayer et al 1988, Murphy et al 1992, Cuenod et al 1993).

Investigations performed in senile beagle dogs proved that, using nuclear magnetic resonance as a tool, volumetric changes could be found in the brains of aged dogs. These studies found a significant increase in the ventricular volume of the dogs after the age of 11 ( $\mathrm{Su}$ et al 1998); additionally, most of the injuries were observed in the frontal cortex and caudate nucleus. This finding suggests that the frontal lobules could be particularly vulnerable to changes in age (Su et al 2005).

Magnetic resonance imaging is also useful in assessing the risk of cerebrospinal fluid collection at the cerebellomedullary cistern. This is the last step in ruling out any neurologic diseases that might mimic CDS, such as inflammatory, infectious, or neoplastic diseases (Golini et al 2009).

In recent years, voxel-based morphometry (VBM) has emerged as a technique to examine regional brain changes associated with normal and pathological aging. Despite its popularity in studies of human aging, the application of VBM in animal models of brain aging is rare. VBM techniques were developed to validate earlier region of interest (ROI) measures of brain aging in dogs and to provide a more comprehensive analysis of local changes in a canine model of brain aging. Specifically, aged males exhibited greater decreases in the internal capsula and cranial nerve bundles compared to decreased volumes in the alveus of the hippocampus in old female dogs (Tapp et al 2006).

Furthermore, white matter (WM) changes observed in vivo in dogs may reflect degenerative changes in myelin sheath integrity or a loss of oligodendrocytes concomitant with aging in humans (Peters 2002 ${ }^{\mathrm{a}}$ ) and non-human primates (Peters 2002 $2^{\mathrm{b}}$ ). The present VBM analysis suggested that morphological brain aging in beagles varies regionally. Further, the present results suggest that, although both sexes show brain atrophy in the frontal and temporal lobes, the extent of brain aging in the frontal lobes is greater in males, while females exhibit greater aging in the temporal lobes (Tapp et al 2006).

Positron emission tomography (PET) is a research technique that allows for the quantitative assessment of the rate of glucose utilization and oxygen consumption. Most patients with Alzheimer's disease show cerebral hypometabolism compared with age-matched controls. These changes correlate with disease severity and may be correlated with neuropsychological test performance. The value of PET studies in determining the stage of disease, documenting progression, and assessing the effects of treatment is unknown (McKhann 1984).

The electroencephalogram has been used as a tool that allows for differential diagnosis with epilepsy processes in the temporal lobe, where behavior changes are often observed. Investigations in human medicine show that patients with Alzheimer's disease exhibited significantly lower D2 and L1 values than those for age-approximated healthy controls. These results suggest that brains afflicted by Alzheimer's disease demonstrate behaviors that are less chaotic than those of normal healthy brains. This paper shows that non-linear analysis can serve as a fruitful tool for detecting relative changes in the complexity of brain dynamics, which cannot be detected by conventional linear analysis. The authors propose that 
non-linear dynamic analyses of the EEGs from patients with Alzheimer's disease will be a diagnostic modality in the appropriate clinical setting (Jeong et al 1998).

\section{BIOMARKERS DIAGNOSIS}

Laboratory biomarkers are important milestones for confirming or establishing a diagnosis in many diseases. They are expected to be sensitive tools for guiding evidence-based medical therapy (Herrmann and Obeid 2011). Some biomarkers possess biological activities and are thought to be toxic to the central nervous system. If so, they may actually be a causal agent that may contribute to disease pathogenesis. In $\mathrm{AD}$, variations of the $\beta$ peptides, tau, phosphorylated tau, lipid peroxides, peroxide products, and toxic sugars are associated with disease. Neuropathological examination of cerebrospinal fluid (CSF) permits a definitive diagnosis of AD (Gendelman 2007). A recent study carried out in healthy beagles (4-16 years old) showed that levels of A $\beta 1-42$, but not A $\beta 1-40$, decreased slightly in the cerebrospinal fluid (CSF) as brain amyloid deposition increased with age (Head et al 2010).

CDS in dogs is not only important as a model of AD for research purposes but is also important from a clinical and veterinary point of view. Therefore, there is an urgent need for reliable biomarkers that can detect the onset of brain amyloid pathology before irreversible neurodegeneration occurs.

The availability of biomarkers and more refined neuropsychological tests in veterinary clinics may enable the definition of a canine model for mild cognitive impairment in the near future (Sarasa and Pesini 2009). Recent research has found that the canine model is a suitable model for AD from the molecular point of view because APP and most of the enzymatic machinery for its processing bear extensive homology between dogs and humans (Sarasa and Pesini 2009).

Plasma A $\beta 1-42$ and A $\beta 1-40$ peptides have been proposed as non-invasive peripheral biomarkers to distinguish between cognitively healthy people and patients with mild cognitive impairment (MCI) with a high degree of sensitivity and specificity (Mehta et al 2000, Lopez et al 2008, Blasco et al 2008).

Studies by González-Martinez et al (2011) analyzed plasma levels of $A \beta 1-42$ and $A \beta 1-40$ in relation to age and cognitive dysfunction in dogs. Their study hypothesized that plasma $\mathrm{A} \beta$ peptide levels would differ among the different groups of animals and would relate to the presentation of cognitive dysfunction in the aged groups (Pesini et al 2009).

The concentrations of these two $A \beta$ isoforms were correlated, and $A \beta 1-40$ levels were higher than $A \beta 1-42$ levels in all the study groups. Both of these features agreed with the results reported in the majority of similar studies conducted in humans (Schupf et al 2008). Plasma A $\beta$ peptide levels tended to decrease with age in cognitively intact dogs (i.e., in young, middle-aged and cognitively unimpaired age groups). In particular, dogs less than 4 years old showed significantly higher $A \beta 1-42$ and $A \beta 1-40$ levels, as well as higher $A \beta 42 / 40$ ratio values, than those greater than 9 years old (González-Martinez et al 2011). This finding suggests that the observed reduction of plasma $A \beta 1-42$ and $A \beta 1-40$ concentrations in cognitively unimpaired aged dogs might also be a consequence of increasing brain amyloid deposition. Increases in A $\beta 1-42$ plasma levels and the $A \beta 42 / 40$ ratio were detected in dogs suffering from CDS when compared with cognitively unimpaired dogs (González-Martinez et al 2011).

The investigation of brain aging in dogs also deserves attention from a veterinary point of view. As in the case of human medical technologies, improvements in veterinary medicine and husbandry have contributed to the longer lifespans of our domestic animals, with the unwanted side effect of a greater incidence of age-related neurodegenerative diseases (Landsberg 2005). Due to this, pioneer investigations have designed tools that have produced highly specific and sensitive antibodies against the two major isoforms of the $A \beta$ amyloid to aid in this research, and they are currently exploring the use of these $A \beta$ immunogens in the search for premorbid biomarkers and immunotherapeutic strategies (Sarasa and Pesini 2009).

On the other hand, Ray et al (2007) showed a molecular test for Alzheimer`s disease could lead to better treatment and therapies. They found 18 signaling proteins in blood plasma that could be used to classify blinded samples from Alzheimer`s and control subjects with close to $90 \%$ accuracy and to identify patients who had mild cognitive impairment that progressed to Alzheimer`s disease 2-6 years later. Biological analysis of the 18 proteins points to systemic dysregulation of hematopoiesis, immune response, apoptosis and neuronal support in presymptomatic Alzehimer`s disease. Therefore, this findings in proteomic and metabolomic could open the way for diagnosis and pharmacologic response to a therapeutic agent, that in the future could be used in animal models and veterinary medicine.

\section{BEHAVIOR DIAGNOSIS}

The zoopsychiatric evaluation plays a fundamental role in identifying dementia and in its differential diagnosis. The majority of signs are the result of psychiatric alterations that are consequences of pathological processes that have previously altered the organism. In this sense, and according to some authors, the most effective way to detect this condition is through the use of behavioral questionnaires in the routine geriatric clinic (Head 2001, Head and Zicker 2004), obtained from a series of questionnaires that intended to clarify the patients' CDSaffected behavior (Rofina et al 2001, Cotman et al 2002). The ARCAD scale (evaluation of age-related cognitive and effective disorders) has also been presented (Colle 
et al 2000, Pageat 2001), in which the dogs' behavior is analyzed through a "formal questionnaire" that assesses the behavioral categories affected by cognitive and affective disorders, including orientation, recognition of family members and other animals, inappropriate elimination at home, and alterations in sleep-wake patterns.

A large number of theories and scales has been proposed to confirm CDS in dogs (Colle et al 2000, Landsberg et al 2003, Pugliese et al 2005). However, the selection of scoring criteria has not been clear and tends to be subjective. Although these data provide a useful basis, it is important to perfect the identification and classification of such high-prevalence behaviors to evaluate the senile dogs' cognitive profile as an adequate clinical evaluation tool.

Studies conducted by Salvin et al (2011) distributed polls to dog owners from Australia, the United States, New Zealand and the United Kingdom, and they found that behavioral signs support the neuropathophysiology of canine patients with CDS with a high level of precision. This poll, named the CCDR (canine cognitive dysfunction rating) evaluation scale, evaluates 13 behavioral items related to problems in orientation (blank stare, disorientation and getting lost at home), memory (lacking in owner recognition and inappropriate elimination at home), apathy (decrease in the amount of time dedicated to activity), smelling inability (difficulty to find food) and locomotion. This study shows a high diagnostic accuracy $(99.3 \%)$ and correct estimation of the prevalence in senile dogs with this disease, due to its favorable psychometric properties (Salvin et al 2011).

A definitive diagnosis of the disease requires histopathologic confirmation. Clinical diagnosis of possible cognitive dysfunction may be made in the presence of other significant diseases (McKann et al 1984). The aged dog brain could be a useful model for understanding the pathogenesis of early $\mathrm{AD}$, and these animals represent a valuable resource for the preclinical testing of therapeutic approaches that could be used to diagnose and treat this devastating disorder in man (Yu et al 2011).

\section{TREATMENT}

Treatment must be focused on slowing the progression of cognitive loss through the use of the following techniques and improvement programs, with emphasis on physical activity, nutrition, environmental enrichment and psychopharmacology. The ideal therapy should include all of the indicated techniques because they possess a synergic effect that translates into better results.

\section{PHYSICAL ACTIVITY}

Recent research has shown that physical activity contributes to healthier brain aging, and this research has increased the interest in understanding the influence of physical activity as a potential protection factor against deterioration and dementia (Lautenschlager et al 2011). Physical activity intervenes in different ways in cognitive efficiency, visual, verbal and working memory, execution functions, and visual and auditory attention.

Physical activity improves blood flow to the brain, decreasing infarct risk, dementia and cognitive decline. Activity could stimulate the growth of nervous cells in the hippocampus, the brain region that participates in memory functions. According to experts, this would help the brain build a sort of reserve to prevent future mental impairment (Landsberg 2005, Pérez-Guisado 2007). On the other hand, physical activity has been proven to exert effects over angiogenesis, synaptogenesis, increases in the brain's blood flow, decreases in inflammation and changes in neurotransmitter balance, which results in an improvement in the syndrome (Lista et al 2010).

Some studies have shown the impact of physical exercise as a brain protection factor against the negative effects of chronic stress, stating that one of the main subjacent mechanisms of the way in which chronic stress damages the brain is an increase in oxidative stress with an increase in lipid peroxidation, which later exerts effects on neurogenesis in the hippocampus (Nakajima et al 2010).

Some researchers consider physical exercise to be a possible behavioral intervention to improve health and cerebral plasticity (Cotman et al 2002). However, in aged dogs, there are painful pathological processes that could interfere with the practice of therapeutic physical activities, which include coordination exercises, strengthening exercises, hydrotherapy, massages, thermo- and cryotherapy and passive range of motion (Mlacnik et al 2006, Rivera 2007, Crook et al 2007, Holler et al 2010).

\section{NUTRITION}

Due to the disease's development and its large impact on an organic level, diet is one of the most important aspects in the CDS disease process in dogs. Multiple researchers have proven that a variety of nutritional strategies, such as the combination of antioxidants with certain fatty acids, essential minerals, vitamins, mitochondrial factors and other nutrients, as well as caloric restriction, may be effective in reducing the neuropathology associated with cognitive dysfunction in dogs and in decreasing neuronal degeneration and favoring memory preservation.

Antioxidants. Some studies suggest that antioxidants may be beneficial in the aging of the brain and may play an important role in preventive intervention. Thus, numerous studies have demonstrated that diets supplemented with vitamins $B, E$ and $C$ and other antioxidants, such as $\beta$-carotene, selenium, $\beta$-lipoic acid, and a series of flavonoids and carotenoids (e.g., spinach stem, celery, blueberries, onion, black chocolate, broccoli, apple, tea, parsley, soya, eggplant, tomato pulp, grape extract, carrot, grano- 
la and citrus pulp) can reduce the risk of suffering agerelated neurodegenerative diseases (Hagen et al 2002).

A study by Shukkit (1999) compared the effects of certain red fruit components (blackberries, strawberries, raspberries, blueberries, currants, etc.) on cognitive results. The study examined the results obtained from older rats in neurocognitive tests as well as the possible action mechanisms and their relation to biochemical changes in the brain. The results concluded that the components of red fruits had a beneficial effect on the rats' performance during tilted screen tests (a standard and valid test that evaluates neurocognitive function and rodent behavior), improving their psychomotor functions. Additionally, blueberry extracts significantly increased the release of striatal dopamine relative to the control group. On the other hand, there was a greater neurocognitive performance in rats when measuring their frequency of falls from the tilted screen. The release of dopamine and the obtained results suggest that there is an effect associated with the wide range of red fruit extracts; however, the anthocyanin present in red fruits is not the only component responsible for these improvements. Other studies have found that supplements with blueberry extract significantly increased the level of insulin-like growth factor (IGF-1) in the hippocampus. These biomarkers are significantly associated with lower levels of errors in cognitive tests and improvements in the rodents' working memory performance (Papandreou et al 2009).

The use of ginkgo biloba, acetyl-L-carnitine, Sadenosylmetionine and phosphatidylserine, which have been used as mental dexterity and memory enhancers, is now being studied in animals. Certain authors suggest that, in addition to its antioxidant effects, the gingko biloba vegetable presents with anti-inflammatory, brain vasodilating, mitochondrial function-enhancing and MAO enzyme-inhibiting properties (Launer et al 1999, Landsberg 2005, Osella et al 2007). In this way, it causes a decrease in the severity of clinical signs observed in patients with CDS. Additionally, natural compounds of animal origin, such as propolis, are now the objects of research due to their antioxidant and neuroprotective properties (Shimazawa et al 2005). However, there are still no studies that describe the positive effects of this compound in CDS.

Likewise, the use of melatonin is being studied with the aim of determining whether this hormone inhibits the production of free radicals (Kline 2002). Certain levels of omega-3 fatty acids play an important role in the health of the cell membranes and offer a high anti-inflammatory potential (Youdim et al 2000).

Caloric restriction. It is also important to note that caloric restriction is the only known measure that increases the average life span of a variety of animals, from rats to primates (Beckman and Ames 1998, Kealy et al 2002). It also promotes the maintenance of youth in terms of general health, memory and learning. Caloric restriction maintains mitochondrial function while controlling oxidant production (Hart et al 2009). Thus, in one study, rats were administered a mitochondrial metabolite (carnitine) and an antioxidant (lipoic acid), which reverted the agerelated mitochondrial degenerative changes and decreased oxidative damage in hepatic cells. It also increased the joining affinity of enzymes related to the brain and memory (Hagen et al 1998, Liu et al 2002). This work with rats led other authors to study the performance of senile dogs under laboratory conditions with tests that involved discrimination tasks. One-year short-term studies revealed that supplementing the diet with carnitine and lipoic acid, as well as vitamins $\mathrm{E}$ and $\mathrm{C}$, significantly reduced the impairment in the performance of old dogs in those discrimination tasks (Millgram et al 2002).

Medium chain triglycerides. It has been recently suggested that there is a large decrease in brain glucose metabolism in dogs and that these decreases contribute to the increase in age-related cognitive damage. One way to counteract this metabolic deficit is based on the use of nutritional supplements, such as medium chain triglycerides (MCTs), which increase the organism's production of ketone bodies and allow these components to be used as an alternative form of energy (Henderson 2004). Dietary supplements such as medium chain triglycerides increase ketone body levels in the brain, and neurons could potentially use these substances to make up for the glucose deficit produced in neurodegenerative diseases (Pan et al 2010).

\section{ENVIRONMENTAL ENRICHMENT}

It has been demonstrated that an enriched environment increases the mental stimulation of dogs with dementia, which favors the installment of behavior intervention techniques by the owners in relearning common tasks, such as domestic habits. Any type of mental or cognitive stimulation must be implemented in a gradual way, as dogs with CDS have a limited capacity for concentration (Cline 2011). It is important to establish brain training and mental stimulation programs during walks and even at home, using cognitive toys and search and exploration games. Social enrichment is also important, dedicating more time to walks, interaction games and obedience training. Contact with humans and other dogs in different places and circumstances are helpful (Milgram et al 2004). As age increases, the animal's capacities for sensation decrease, so it is important to implement a certain degree of stimulation to maintain brain activity in its best condition. Stimulating sensory pathways (sight, smell, taste, etc.) is necessary, as the deterioration produced in senile animals allows these animals to increase their state of security and to decrease anxiety. It is advisable to increase contact with new smells, tastes and sounds. 
The ability to observe exterior activity through a window and the opportunity to view the television when left alone should be allowed (Head and Zicker 2004).

\section{PHARMACOLOGICAL AGENTS}

Pharmacological treatment should aim to palliate associated behavior problems and cognitive disorders present in senile patients. Considering that physiological changes may present themselves in these animals, a complete physio-clinical evaluation should be performed before medicating, with the aim of following-up with the patient and detecting the development of any side effects.

In the canine brain, selegiline increases 2-phenylethylemine, which works as a neuromodulator and enhances the function of dopamine and catecholamines (Landsberg 2005). It also shows a mild antidepressant effect derived from the same action mechanism, which simultaneously confers a neuroprotector effect. Studies of selegiline showed a decrease in the progression of the degenerative changes of patients with $\mathrm{AD}$ and a significant improvement in dogs with CDS. Likewise, following selegiline treatment, short-term memory improves, signs associated with cognitive dysfunction decrease, and the life span of old dogs increases (Neilson et al 2001). Therefore, altering neurotransmitter concentrations through the use of selegiline seems to be the most effective pharmacological therapy against the progression of clinical signs in dogs with CDS. In dogs that show alterations in their sleep/wake cycle, it is recommended to administer selegiline in the mornings. Response to therapy may be seen in a few days, although improvement is properly seen in the first two weeks. It must be considered that in some cases, a relapse of $15 \%$ may appear in the treated dogs.

Other pharmacological agents with notable efficiency are nicergoline and propentofylline. Both drugs produce peripheral vasodilatation with an increase in brain risk, which produces an improvement in brain blood flow. The result is the stimulation of psychological functions of memorization and learning, thereby producing a moderate improvement in the cognitive functions of senile dogs. The use of vitamin complexes that include vitamins E, B and $\mathrm{C}$, as well as antioxidant agents, is equally interesting, as there are a great variety of these products on the market (Landsberg 2006).

\section{CONCLUSIONS}

Given the veterinarian's role as a guarantor of the quality of life of geriatric dogs, training in the knowledge and detection of the clinical signs associated with CDS is very important, as is the scientific criteria with which the therapeutic management will be approached. On the other hand, considering the existing relationship between dementia syndrome and aging, there are many dogs that are at risk of suffering this disease, and even more dogs will be at risk if the continuous growth of the geriatric canine population is taken into account. Therefore, it is necessary to continue and further the relevant research, with the goal of acquiring deeper knowledge on the most important aspects of this highly prevalent pathology, such as its diagnosis, treatment and prevention, which could help decrease the impact generated by its effects.

\section{REFERENCES}

Adams B, A Chan, H Callahan and NW Milgram. 2000. The canine as a model of human cognitive aging. recent developments. Prog Neuro-Psychoph 24, 675-692.

Ames BN, MK Shigenaga, TM Hagen. 1993. Oxidants, antioxidants, and the degenerative diseases of aging. P Natl Acad Sci USA 90, 7915-7922.

Anderson I, C Adinolfi, S Doctrow, K Huffman, KA Joy, B Malfroy, PSodeu, HT Rupniak, JC Barnes. 2001. Oxidative signalling and inflammatory pathways in Alzheimer's disease. Biochem Soc Symp 67, 141-149.

Azkona G, S García-Belenguer, G Chacón, B Rosado, M León, J Palacio. 2009. Prevalence and risk factors of behavioural changes associated with age related cognitive impairment in geriatric dogs. J Small Anim Pract 50, 87-91.

Bain MJ, BJ Hart, KD Cliff, WW Ruehl. 2001. Predicting behavioural changes associated with age-related cognitive impairment in dogs. J Am Vet Med Assoc 218,1792-1795.

Beckman K, B Ames. 1998. The free radical theory of aging matures. Physiol Rev 78, 547-581.

Bonagura J. 2000. Kirk Current Veterinary Therapy XIII. J Small Anim Pract 61, 53-56.

Borras D, I Ferrer, M Umarola. 1999. Age-related changes in the brain of the dog. Vet Pathol 36, 202-211.

Boutet I, M Ryan, V Kulaga, C McShane, LA Chistie, M Freedman, NW Milgram. 2005. Age-associated cognitive deficits in humans and dogs: a comparative neuropsychological approach. Prog Neuro-Psychoph 29, 433-441.

Briones F, T Cáceres, M Jarpa. 2010. Detección de $\beta$-amiloide, proteína TAU hiperfosforilada y ubiquitina por técnica de inmunohistoquímica en cerebros de caninos mayores de 10 Años. Int J Morphol 28, 1255-1261.

Caermelli D, GE Swan, T Reed, GD Schellenberg, JC Christian. 1999. The effect of Apolipoprotein e4 in the relationships of smoking and drinking to cognitive function. Neuroepidemiology 18, 125-133.

Campbell S, A Trettien, B Kozan. 2001. A non comparative open-label study evaluating the effect of selegiline hydrochloride in a clinical setting. Vet Ther 2, 1-9.

Cerdá C, V Salvador, M Ocete, R Torregrosa, M Fandos-Sánchez, T Sáez. 2009. Estrés oxidativo, envejecimiento y cáncer. En: Sastre J, Ramón R, Pamplona R (eds). Biogerontología médica. ERGON, Madrid, España, Pp 71-85.

Cline J. 2011. Introduction: nutrition, geriatrics, and behavior. Top Companion Anim M 26, 1.

Colle A, J Hauw, F Crespeau, T Uchihara, H Akiyama, F Checler, P Pageat, C Duykaerts. 2000. Vascular and parenchimal $\beta$ amiloyd deposition in the aging dog: correlation with behaviour. Neurobiol Aging 21, 695-704.

Cotman C, E Head, B Muggenburg, S Zicker, N Milgram. 2002. Brain aging in the canine: a diet enriched in anti- 
oxidants reduces cognitive dysfunction. Neurobiol Aging 23, 809-818.

Crook T, GJ Larrabee. 1991. Diagnosis, assessment and treatment of age-associated memory impairment. $\mathrm{J} \mathrm{Neu}$ ral Transm 33, 1-6.

Crook T, C McGowan, M Pead. 2007. Effect of passive stretching on the range of motion of osteoarthritic joints in 10 Labrador retrievers. Vet Rec 160, 545-547.

Cuenod CA, A Denys, JL Michot, P Jehenson, F Forette, D Kaplan, A Syrota, F Boller. 1993. Amygadala atrophy in Alzheimer's disease. An in vivo magnetic resonance imaging study. Arch Neurol 50, 941-945.

Cummings BJ, DW Cotman. 1995. Image analysis of $\beta$-amyloid load in Alzheimer's disease and relation to dementia severity. Lancet 346, 1524-1528.

Cummings BJ, E Head, WW Ruehl, NW Milgram, CW Cotman. 1996. The canine as an animal model of human aging and dementia. Neurobiol Aging 17, 259-268.

Cumsee C, S Landshamer. 2006. Molecular insights into mechanisms of cell death program: role in the progression of neurodegenerative disorders. Curr Alzheimer Res 3, 269-283.

Drayer BP. 1988. Imaging of the aging brain. Part II. Pathologic conditions. Radiology 166,797-806.

Ferrari E, L Cravello, B Muzzoni, D Casarotti, M Paltro, SB Solerte, M Fioravanti, G Cuzzoni, B Pontiggia, F Magri. 2001. Agerelated changes of the hypothalamic-pituitaryadrenal axis: pathophysiological correlates. Eur J Endocrinol 144, 319-329.

Frank D. 2002. Cognitive dysfunction in dog. Prakt Tierarzt 84, 184-186.

Frisoni GB, NC Fox, CR Jack, P Scheltens, PM Thompson. 2010. The clinical use of structural MRI in Alzheimer disease. Nat Rev Neurol 6, 67-77.

Gallego D, J Figueroa, C Orozco. 2010. Síndrome de disfunción cognitiva de perros geriátricos. Rev MVZ Cordoba $58,142-154$.

Gendelman HE. 2007. Biomarkers, laboratory, and animal models for the design and development of adjunctive therapies for HIV-1 dementia and other neuroinflammatory disorders. J Neuroimmune Pharm 49, 343-344.

Godoy R. 2004. Ubicación y reconocimiento de placas seniles, degeneración neurofibrilar y $\beta$-amiloide en cerebros de caninos geriátricos. Memoria de título, Universidad Iberoamericana de Ciencias y Tecnología, UNICIT, Santiago, Chile.

Goedert M. 1993. Tau protein and the neurofibrillary pathology of Alzheimer`s disease. Trends Neurosci 16, 460-465.

Golini L, R Colangeli, V Tranquillo, M Mariscoli. 2009. Association between neurologic and cognitive dysfunction signs in a sample of aging dogs. $J$ Vet Behav 4, 25-30.

González-Martínez A, B Rosado, P Pessini, ML Suárez, G Santamarina, S García-Belenguer, A Villegas, I Monleón, M Sarasa. 2011. Plasma $\beta$-amyloid peptides in canine aging and cognitive dysfunction as a model of Alzheimer's disease. Exp Geront 46, 590-596.

Gra MS, PN Padron, RJJ Llibre. 2002. Péptido $\beta$ amiloide, proteína Tau y enfermedad de Alzheimer. Rev Cubana Invest Biomed 21, 253-261.

Guimera A, X Girones, F Cruz-Sánchez. 2002. Actualización sobre la patología de la enfermedad de Alzheimer. Insti- tuto de Ciencias Neurológicas y Gerontológicas. Rev Esp Patol 35, 21-48.

Hagen TM, RT Ingersoll, CM Wehr, J Lykkesfeldt, V Vinarsky, JC Bartholomew. 1998. Acetyl-L-carnitine fed to old rats partially restores mitochondrial function and ambulatory activity. P Natl Acad Sci USA 95, 9562-9566.

Hagen TM, J Liu, J Lykkesfeldt, CM Wehr, RT Ingersoll, V Vinarsky, JC Bartholomew, BN Ames. 2002. Feeding acetyl-L-carnitine and lipoic acid to old rats significantly improves metabolic function while decreasing oxidative stress. P Natl Acad Sci USA 99, 870-875.

Hart BL, LA Hart, MJ Rain. 2009. Aspectos de la conducta de los perros ancianos. Tratamiento de la conducta canina y felina. $2^{\mathrm{a}}$ ed. Inter-Médica, Buenos Aires, Argentina, Pp 195-202.

Head E. 2001. Brian aging in dogs: Parallels with human brain aging and Alzheimer's disease. Vet Thera 2, 247-260.

Head E, S Zicker. 2004. Nutraceuticals, aging, and cognitive dysfunction. Vet Clin N Am Small Anim 34, 217-228.

Head E, V Pop, F Sarsoza, R Kayed, TL Beckett, CM Studzinski, JL Tomic, CG Glabe, P Murphy. 2010. Amyloid- $\beta$ peptide and oligomers in the brain and cerebrospinal fluid of aged canines. J. Alzheimers Dis 20, 637-646.

Heath ES, SB Barabas, P Craze. 2007. Nutritional supplementation in cases of canine cognitive dysfunction- A clinical trial. Appl Anim Behav Sci 105, 284-296.

Henderson ST. 2004. High carbohydrate diets and Alzheimer's disease. Med Hypotheses 62, 689-700.

Herrmann W, Obeid R. 2011. Biomarkers of neurodegenerative diseases. Clin Chem Lab Med 49, 343-344.

Holler P, V Brazda, B Dal-Bianco, E Lewy, M Mueller, C Peham, B Bockstahler. 2010. Kinematic motion analysis of the joints of the forelimbs and hind limbs of dogs during walking exercise regimens. Am J Vet Res 71, 734-740.

Ilkeda D, C de Rivera, M Milgram. 2005. Pharmaceutical and other commercial uses of the dog model. Prog NeuroPsychoph 29, 355-360.

Ingram DK, N Williams. 2002. Neurobiology of cognitive dysfunction syndrome in dogs. Simposio clinical and nutritional management of senior dogs and cats. Congreso mundial WSAVA-FECAVA-AVEPA, Granada, España, Pp 31-36.

Jeong J, KY Soo, HH Seol. 1998. Non-linear dynamical analysis of the EEG in Alzheimer's disease with optimal embedding dimension. Clin Neurophysiol 106, 220-228.

Jorm A. 2000. Risk factors for Alzheimer's diseases. In: O'Brien J, Ames D, Burns A (eds). Dementia. $2^{\text {nd }}$ ed. Arnold London, UK, Pp 3-8.

Kealy RD, DF Lawler, JM Ballam, SL Mantz, DN Biery, EH Greeley, G Lust, M Segre, GK Smith, HD Stowe. 2002. Effect of diet restriction on life span and age-related changes in dogs. J Am Vet Med Assoc 220, 1315-1320.

Kline KL. 2002. Complementary and Alternative Medicine for Neurologic Disorders. Top Companion Anim Med 17, 2533.

Lafora G. 1914. Neoformaciones dendriticas en las neuronas y alteraciones de la neuroglia en el perro senil. Trab $L a b$ Invest Biol Univ Madrid 12, 39-53.

Landsberg G, W Ruehl. 1997. Geriatric behavioral problems. Vet Clin N Am Small Anim 27, 1537-1559.

Landsberg G. 1998. Behavior problems in the geriatric dog and cat. Abstract from friskies small animal behavior sympo- 
sium 27, 1537-1559.

Landsberg G, W Hunthausen, L Ackerman. 2003. The effects of aging on the behaviour of senior pets. In: Landsberg G, Hunthausen W, Ackerman L (eds). Handbook of Behaviour Problems of the Dog and Cat. $2^{\text {nd }}$ ed. Saunders, Edinburgh, UK, Pp 554.

Landsberg G. 2005. Therapeutic agents for the treatment of cognitive dysfunction syndrome in senior dogs. Prog Neuro-Psychoph 3, 471-479.

Landsberg G. 2006. Therapeutic options for cognitive decline in senior pets. J Am Anim Hosp Assoc 42, 407-413.

Landsberg GM, T Deporter, JA Araujo. 2011. Clinical signs and management of anxiety, sleeplessness, and cognitive dysfunction in the senior pet. Vet Clin N Am Small Anim 41, 565-590.

Laughlin GA, E Barrett-Connor. 2000. Sexual dimorphism in the influence of advanced aging on adrenal hormone levels: the Rancho Bernardo study. J Clin Endocr Metab 85, 561-568.

Launer LJ, K Andersen, M Dewey, L Lettenneur, A Ott, L Amaducci. 1999. Rates and risk factors for dementia and Alzheimer's disease. Results from EURODEM pooled analyses. Neurology 52, 74-78.

Lautenschlager NT, K Cox, EV Cyarto. 2011. The influence of exercise on brain aging and dementia. Biochim Biophys Acta 3, 474-781.

Lista I, G Sorrentino. 2010. Biological mechanisms of physical activity in preventing cognitive decline. Cell Mol Neurobiol 30, 493-503.

Liu J, E Head, AM Gharib, WJ Yuan, RT Ingersoll, TM Hagen, CW Cotman, BN Ames. 2002. Memory loss in old rats is associated with brain mitochondrial decay and RNA/ DNA oxidation: Partial reversal by feeding acetyl- Lcarnitine and /or R-alpha-lipoic acid. Proc Natl Acad Sci USA 99, 356-361.

Liu CY, CF Lee, YH Wei. 2009. Role of reactive oxygen species-elicited apoptosis in the pathophysiology of mitocondrial and neurodegenerative diseases asociate with mitochondrial DNA mutations. J Formos Med Assoc 108, 599-611.

Llibre J, M Guerra. 1999. Enfermedad de Alzheimer. Situación actual y estrategias terapéuticas. Rev Cubana Med 38, 134-142.

Lopez OL, LH Kuller, PD Mehta, JT Becker, HM Gach, RA Sweet, YF Chang, R Tracy, ST DeKosky. 2008. Plasma amyloid levels and the risk of AD in normal subjects in the cardiovascular health study. Neurology 70, 1664-1671.

Lorenzo J, L Fontán. 2003. Las fronteras entre el envejecimiento cognitivo normal y la enfermedad de Alzheimer. El concepto de deterioro cognitivo leve. Rev Med Uruguay 19, 4-13.

Manteca X. 2003. Etología clínica veterinaria del perro y del gato. $3^{a}$ ed. Multimédica, Barcelona, España, Pp 198-200.

McKhann G, D Drachman, M Folstein, R Katzman, D Price, EM Stadlan. 1984. Clinical diagnosis of Alzheimer's disease: Report of the NINCDS-ADRDA Work Group under the auspices of Department of Health and Human Services, Task Force on Alzheimer's Disease. Neurology 34, 939.

Mehta PD, T Pirttila, SP Mehta, EA Sersen, PS Aisen, HM Wisniewski. 2000. Plasma and cerebroespinal fluid levels of amyloid $\beta$ proteins $1-40$ and 1-42 in alzheimer disease. Arch Neurol Chicago 57, 100-105.

Mentzel E, M Juarez. 2005. Alteraciones del sueño y el animo en la disfunción cognoscitiva canina. Memorias del $V$ Congreso Nacional de la Asociación de Veterinarios Especializados en Animales de Compania de Argentina (AVEACA), Buenos Aires, Argentina, Pp 12-15.

Milgram NW, E Head, B Muggenburg, B D Holowachuk, H Murphey, J Estrada, CJ Ikeda-Douglasa, SC Zicker, CW Cotman. 2002. Landmark discrimination learning in the dog: Effects of age on antioxidant fortified food, and cognitive strategy. Neurosci Biobehav Rev 26, 679-695.

Milgram NW, E Head, SC Zicker SC, C Ikeda-Douglas, H Murphey, BA Muggenberg, CT Siwak, PD Tapp, SR Lowry, CW Cotman. 2004. Long-term treatment with antioxidants and a program of behavioral enrichment reduces age-dependent impairment in discrimination and reversal learning in beagle dogs. Exp Gerontol 39, 753-765.

Mlacnik E, B Bockstahler, M Muller, M Tetrick, R Nap, J Zentek. 2006. Effects of caloric restriction and a moderate or intense physiotherapy program for treatment of lameness in overweight dogs with osteoarthritis. J Am Vet Med Assoc 229, 1756-1760.

Morelli L, EM Castaño. 2004. Buscando blancos terapéuticos para las enfermedades neurodegenerativas: Pin 1 y tau en la mira. Ciencia Hoy 14, 30-33.

Murphy DG, C De Carli, MB Schapiro, SI Rapoport, B Horwitz. 1992. Age-related differences in volumes of subcortical nuclei, brain matter, and cerebrospinal fluid in healthy men as measured with magnetic resonance imaging. Arch Neurol Chicago 49, 839-845.

Nakajima S, I Ohsawa, S Ohta, M Ohno, T Mikame. 2010. Regular voluntary exercise cures stress-induced impairment of cognitive function and cell proliferation accompanied by increases in cerebral IGF-1 and GST activity in mice. Behav Brain Res 211, 178-184.

Neilson JC, BL Hart, KD Cliff, WW Ruehl. 2001. Predicting behavioral changes associated with age-related cognitive impairment in dogs. J Am Vet Med Assoc 218, 787-791.

Osella MC, G Re, R Odore, C Girardi, P Badino, R Barbero, L Bergamasco. 2005. Canine cognitive dysfunction: prevalence, clinical signs and treatment with a nutraceutical. In: Mills D, Levine E, Landsberg GM (eds). Current Issues and Research in Veterinary Behavioral Medicine. Purdue University Press, West Lafayette, USA, Pp 66-72.

Osella MC, G Re, R Odore, C Girardi, P Badino, R Barbero, L Bergamasco. 2007. Canine cognitive dysfunction syndrome: Prevalence, clinical signs and treatment with a neuroprotective Natraceutical. Appl Anim Behav Sci 105, 297-310.

Pageat P. 2001. Description, clinical and histological validation of the A.R.C.A.D. score (evaluation of age-related cognitive and affective disorders). Proc Third International Cong Vet Behav Med 83, 58.

Pan Y, B Larson, J Araujo, W Lau, C De Rivera, R Santana, A Gore, NW Milgram. 2010. Dietary supplementation with medium-chain TAG has long-lasting cognition-enhancing effects in aged dogs. Brit J Nutr 103, 1746-1754.

Papandreou M, A Dimakopoulo, ZI Linardaki, P Cordopatis D Klimis-Zacas, M Margarity, FN Lamari. 2009. Effect of a polyphenol-rich wild blueberry extract on cognitive performance of mice, brain antioxidant markers and ace- 
tylcholinesterase activity. Behav Brain Res 198, 352-358.

Pérez-Guisado J. 2007. Canine cognitive dysfunction síndrome. Rev Ele Clin Vet 2, 1-4.

Pesini P, M Boada, P Martínez-Lage, L Tárraga, I Monleón, V Pérez-Grijalva, I San-José, J Porcel-Carbonel, A Gutiérrez-Blanco, M Sarasa. 2009. Differences in $\beta$ amyloid pool in blood discriminate between amnesic mild cognitive impairment patients and healthy controls. $J$ Nutr Health Aging 13, 850.

Peters A. $2002^{\mathrm{a}}$. The effects of normal aging on myelin and nerve fibers: a review. J. Neurocytol 31, 581-593.

Peters A. $2002^{\text {b }}$. Structural changes in the normally aging cerebral cortex of primates. Prog Brain Res 136, 455-465.

Pugliese P, JL Carrasco, C Andrade, E Mas, J Mascort, N Mahy. 2005. Severe cognitive impairment correlates with higher cerebrospinal fluid levels of lactate and pyruvate in a canine model of senile dementia. Prog Neuro-Psychoph 24, 675-692.

Pugliese M, J Mascort, N Mahy, I Ferrer. 2006. Diffuse $\beta$-amyloid plaques and hyperphosphorylated tau are unrelated processes in aged dogs with behavioral deficits. Acta Neuropathol 112, 175-183.

Ray S, M Britschgi, C Herbert, Y Takeda-Uchimura, A Boxer, K Blennow, LF Friedman, D Galasko, M Jutel, A Karydas, J Kaye, J Leszek, B Miller, L Minthon, J Quinn, G Rabinovici, W Robinson, M Sabbagh, Y So, DL Sparks, M Tabaton, J Tinklenberg, J Yesavage, R Tibshirani, T Wyss-Coray. 2007. Classification and prediction of clinical Alzheimer's diagnosis based on plasma signaling proteins. Nat Med 13, 1359-1362.

Rivera PL. 2007. Canine rehabilitation therapies I and II. Proceedings of the 79th Annual Western Veterinary Conference, Las Vegas, USA.

Rofina JE, I Van der Meer, M Goossens, M Secrève, AM Ederen van, M Schilder. 2001. Preliminary inquiry to assess behavior changes in aging pet dogs. In: Bely M (ed). Amyloid and Amyloidosis IX. Apathey A editores, Budapest, Hungary.

Rofina JE, K Singh, A Skoumalova-Vesela, AM Van Ederen, AJAM van Asten, J Wilhelm, E Gruys. 2004. Histochemical accumulation of oxidative damage products is associated with Alzheimer-like pathology in the canine. Amyloid 11, 90-100.

Rosaldo F. 2006. El síndrome de disfunción cognitiva. ¿Alzheimer en perros?. Rev AMMVEPE 17, 70-77.

Ruehl WW, DS Bruyette, A De Paoli, CW Cotman, E Head, NW Milgran, BJ Cummings. 1995. Canine cognitive dysfunction as a model for human age-related cognitive decline, dementia and Alzheimer's disease: clinical presentation, cognitive testing, pathology and response to 1deprenyl therapy. Prog Brain Res 106, 217-225.

Salvin HE, PD McGreevy, PS Sachdev, MJ Valenzuela. 2010. Underdiagnosis of canine cognitive dysfunction: a cross-sectional survey of older companion dogs. Vet J 184, 277-281.

Salvin HE, PD McGreevy, PS Sachdev, MJ Valenzuela. 2011. The canine cognitive dysfunction rating scale (CCDR): A data-driven and ecologically relevant assessment tool. Vet $J$ 188, 331-336.

Sarasa M, P Pesini. 2009. Natural Non-Trasgenic Animal Mo- dels for Research in Alzheimer's Disease. Curr Alzheimer Res 6, 171-178.

Schupf N, MX Tang, H Fukuyama, J Manly, H Andrews, P Mehta, J Ravetch, R Mayeux. 2008. Peripheral A $\beta$ subspecies as risk biomarkers of Alzheimer's disease Proc Natl Acad Sci USA 105, 14052-14057.

Shettleworth SJ. 2001. Animal cognition and animal behaviour. Anim Behav 61, 277-286.

Shimazawa M, S Chikamatsu, N Morimoto, S Mishima, H Nagai, H Hara. 2005. Neuroprotection by Brazilian green propolis against in vitro and in vivo ischemic neuronal damage. Evid Based Complement Alternat Med 2, 201-207.

Shukitt HB, DE Smith, M Meydani, JA Joseph. 1999. The effects of dietary antioxidants on psychomotor performance in aged mice. Exp Gerontol 34, 797-808.

Skoumalova A, J Rofina, Z Schwippelova, E Gruys, J Wilhelm. 2003. The role of free radicals in canine counterpart of senile dementia of the Alzheimer type. Exp Gerontol 38, 711-719.

Su MY, E Head, WM Brooks, Z Wang, BA Muggenburg, BA Adam, GE Sutherland, R Cotman, CW Nalcioglu. 1998. Magnetic resonance imaging of anatomic and vascular characteristics in a canine model of human aging. Neurobiol Aging 19, 479-485.

Su MY, D Tapp, V Long, L Vua, FY Chena, Y Chua, B Muggenburgd, Y Chioua, C Chena, J Wanga, C Braccoa, E Head. 2005. A longitudinal study of brain morphometrics using serial magnetic resonance imaging analysis in a canine model of aging. Prog Neuro-Psychoph 29, 389-397.

Tapp D, K Head, E Head, NW Milgram, A Muggenburg, Su MY. 2006. Application of an automated voxel-based morphometry technique to assess regional gray and white matter brain atrophy in a canine model of aging. Neuroimage 29, 234-244.

Uchida K, H Nakayama, S Tateyama, N Goto. 1992. Immunohistochemical analysis of constituents of senile plaques and cerebro-vascular amyloid in aged dogs. $J$ Vet Med Sci 54, 1023-1029

Villegas A, B Rosado, A Gonzalez-Martinez, G Chacón, J Palacio, S Garcia Belenguer. 2011. Estudio del eje corticotropo en el envejecimiento normal y patológico en la especie canina. Resúmenes del X Congreso de Especialidades Veterinarias, Valencia, España.

Wang X, H Ding. 2008. Alzheimer's disease: epidemiology, genetics, and beyond. Neurosci Bull 24, 105-109.

Wegiel J, HM Wisniewski, Z Soltysiak. 1998. Region- and celltype-specific pattern of tau phosphorylation in dog brain. Brain Res, 802, 259-266.

Windsor RC, NJ Olby. 2007. Congenital portosystemic shunts in five mature dogs with neurological signs. J Am Anim Hosp Assoc 43, 322-331.

Youdim KA, A Martin, JA Joseph. 2000. Essential fatty acids and the brain: possible health implications. Int J Dev Neurosci 18, 383-399.

Yu CH, GS Song, JY Yhee, JH Kim, KS Im, WG Nho, JH Lee, JH Sur. 2011. Histopathological and immunohistochemical comparison of the brain of human patients with Alzherimer's Disease and the brain of aged dogs with cognitive dysfunction. J Comp Pathol 145, 45-58. 